\title{
INFLUÊNCIA DA PODA DE PRODUÇÃO EM RAMOS DE DIFERENTES DIÂMETROS NO DESENVOLVIMENTO VEGETATIVO E REPRODUTIVO DA PINHEIRA (Annona squamosa L.) $)^{1}$
}

\author{
NILMA OLIVEIRA DIAS ${ }^{2}$, SYLVANA NAOMI MATSUMOTO ${ }^{3}$, TIYOKO NAIR HOJO REBOUÇAS ${ }^{3}$, ANSELMO ELOY \\ SILVEIRA VIANA ${ }^{3}$, ABEL REBOUÇAS SÃO JOSÉ ${ }^{3}$, IVAN VILAS BÔAS SOUZA ${ }^{4}$
}

\begin{abstract}
RESUMO - A poda é uma prática cultural de grande importância para o cultivo da pinheira, influenciando no fenômeno da diferenciação floral de maneira a permitir frutificação fora de época, o que constitui uma importante alternativa econômica para as diversas regiões produtoras. $\mathrm{O}$ experimento foi conduzido no período de 21 de junho a 15 de novembro de 2000, em condições de clima semi-árido, no município de Tanhaçu -BA, com o objetivo de avaliar a influência que a poda de produção, executada em ramos com diferentes diâmetros, exerce sobre o desenvolvimento vegetativo e reprodutivo da pinheira. Utilizou-se o delineamento experimental em blocos casualizados, com sete repetições e três plantas por parcela. Os tratamentos utilizados foram: T1- ramos grossos (11-14 mm de diâmetro); T2- ramos medianos (7-10 mm de diâmetro); T3-ramos finos (3-6 mm de diâmetro). Constatou-se, nas condições estudadas, que o crescimento dos ramos e vigor das flores foram maiores para os ramos grossos, porém, os diferentes diâmetros não influenciaram na qualidade dos frutos (características físicas e químicas).
\end{abstract}

Termos para indexação: produção, indução floral, frutificação.

\section{THE INFLUENCE OF PRUNING ON BRANCHES OF DIFFERENT DIAMETER IN THE VEGETATIVE AND RE- PRODUCTIVE GROWTH OF SUGAR APLLE (Annona squamosa L.)}

\begin{abstract}
Pruning is one of the orchard practices of great importance for the cultivation of sugar apple, influencing the phenomenon of floral induction in order to allow production out of season, which constitutes an important economic alternative for many producing areas conditions. The experiment was carried out from June $21^{\text {st }}$, to November, $15^{\text {th }}$ 2000, in conditions of semi-arid region, in the town of Tanhaçu, Bahia state, Brazil, with the objective of evaluating the influence of pruning branches production with different diameters on vegetative growth, flowering and fruiting of sugar apple. The experimental design was in randomized blocks, seven replications and three plants per plot. The used treatments were: T1- thick branches (11-14 mm of diameter); T2- medium branches (7-10 mm of diameter); T3- thin branches (3-6mm of diameter). The obtained results showed that under the studied conditions branches growth and flower vigour were higher in thick branches, although different diameters did not affect fruit quality (physical and chemical characteristics).
\end{abstract}

Index terms: production, flower induction, frutification.

\section{INTRODUÇÃO}

A pinha (Annona squamosa L.), também conhecida como frutado-conde ou ata, destaca-se economicamente no mercado de fruta fresca, sendo destinada basicamente ao consumo in natura. É cultivada em escala comercial em vários Estados brasileiros, principalmente nas regiões Sudeste e Nordeste, com destaque para São Paulo, Bahia, Alagoas, Sergipe, Pernambuco, entre outros. A poda de produção com desfolha dos ramos é uma prática de grande importância na exploração da cultura, influenciando no fenômeno da diferenciação floral, de maneira a permitir que a produção seja contínua ao longo do ano, inclusive no período da entressafra. Silva (2000) constatou, em estudo envolvendo poda, que existe total viabilidade agronômica e econômica de produzir-se pinha de forma vantajosa nas condições de clima semi-árido, em períodos de entressafra, de forma a aumentar a rentabilidade do produtor, concluindo que as épocas de poda exercem influência sobre o desenvolvimento, mas não interferem no número e percentagem de sementes, sólidos solúveis totais e acidez dos frutos. Para as condições do Rio de Janeiro, o uso da poda de produção, associada à disponibilidade de água, permite concentrar parte da produção nos meses de fevereiro e março e outra em junho e julho (Martelleto, 1997). Em Mirandópolis e Lins, os ramos são podados como manejo de época de produção da segunda safra, concentrando a produção em apenas um mês (Kavati \& Piza Junior, 1997). Cavalcanti (1993) estima que, nos primeiros dois anos, são necessárias em torno de três podas por ano e, nos anos seguintes, duas podas espaçadas de 6 meses serão suficientes no manejo da cultura da pinheira.

Trabalhos relacionados à reprodução da pinheira, como mane- jo das plantas envolvendo podas, justificam-se plenamente por tratar-se de atividades que permitem produzir frutos de qualidade, o que poderá auferir maior lucratividade ao produtor. O presente estudo visou a determinar a influência que a poda de ramos com diferentes diâmetros exerce sobre o desenvolvimento vegetativo e reprodutivo da pinheira.

\section{MATERIAL E MÉTODOS}

O experimento foi conduzido no período de 21-06 a 25-11-2000, no município de Tanhaçu-BA, onde o tipo de clima predominante é o semi-árido. Utilizou-se um plantio comercial de pinheira com três anos de idade, irrigado por microaspersão, formado por plantas oriundas de diversos genótipos e mudas de pé-franco que apresentavam em média 1,19 $\mathrm{m}$ de altura, $0,88 \mathrm{~m}$ de diâmetro de copa e 5,6 cm de diâmetro de tronco a 0,20 m acima do solo, sendo dispostas em espaçamento de 7,0 x 3,5 m. As plantas utilizadas receberam todos os tratos culturais e fitossanitários adequados às necessidades da cultura na região.

O delineamento experimental foi em blocos casualizados, com 3 tratamentos, 7 repetições e 3 plantas por parcela. A instalação dos tratamentos deu-se por ocasião da poda de produção realizada no dia 21 de junho de 2000 , onde os ramos foram reduzidos a $20 \mathrm{~cm}$ de comprimento, totalmente desfolhados (manualmente) e identificados com os seguintes tratamentos: T1- Ramos grossos (11 a 14 mm de diâmetro); T2Ramos medianos (07 a 10 mm de diâmetro); T3 - Ramos finos (03

\footnotetext{
1 (Trabalho 064/2002). Recebido: 18/04/2002; Aceito para publicação: 28/02/2003

${ }^{2}$ Enga $^{\text {a }}$ Agr ${ }^{\mathrm{a}}$., Mestranda, Universidade Estadual do Sudoeste da Bahia, Estrada do Bem Querer, Km 04, Caixa Postal 95 , Vitória da Conquista- BA. Fone: (77) 4214332. E- mail: nodias@terra.com.br

${ }^{3}$ Professores Drs., Universidade Estadual do Sudoeste da Bahia/ Departamento de Fitotecnia e Zootecnia, Estrada do Bem Querer, Km 04, Caixa Postal 95, Vitória da Conquista- BA, CEP 45083 900.Fone : (77) 4248600 E- mail: DFZ@uesb.br

${ }^{4}$ Eng $^{\text {o. }}$ Agr ${ }^{\circ}$., Mestrando, Universidade Federal da Bahia, Cruz das Almas- BA. Fone : (77) 4240634
} 
a 06 mm de diâmetro). Para o estudo do efeito dos tratamentos, consideraram-se o vigor dos ramos e flores, e as características físicas e químicas dos frutos.

A leitura do diâmetro foi feita na região central do ramo, após a poda de produção, com o auxílio de um paquímetro. Em cada planta, foram identificados 6 ramos dentro do intervalo de cada tratamento, totalizando 18 ramos marcados por planta. Dos 6 ramos marcados para cada tratamento, 2 foram reservados apenas para a retirada das flores para posterior determinação do vigor, e os outros 4 foram utilizados para avaliações do crescimento do diâmetro e comprimento dos ramos.

Após o desenvolvimento dos botões florais e ocorrência da antese, realizou-se a polinização artificial, que foi iniciada no dia 04-08-2000. O vigor das flores foi determinado através da massa e dimensões (comprimento e diâmetro maior), quando estas se encontravam no estádio feminino e antes da operação da polinização. Para esta avaliação, foi retirada uma flor proveniente de cada ramo previamente reservado, sendo selecionada a que aparentava maior tamanho, o que totalizou em 6 flores avaliadas por parcela.

Após 20 dias da polinização, iniciou-se o acompanhamento do crescimento dos frutos, o que foi feito através de medições do comprimento (da inserção do talo ao ápice do fruto) e diâmetro maior com o auxílio de um paquímetro. Foram considerados 6 frutos por parcela. Para tanto, realizou-se o desbaste, deixando-se apenas um fruto por ramo.

Os frutos foram colhidos ao atingirem o estádio de maturação fisiológica, determinado pelo início do afastamento dos carpelos, ocasião em que se determinaram o comprimento (da inserção do talo ao ápice do fruto), diâmetro maior e peso dos frutos. Consideraram-se 35 frutos por tratamento, sendo 5 por parcela. Após os frutos atingirem o ponto de consumo, realizaram-se avaliações físicas, obtendo-se a massa de fruto e partes componentes individualmente (casca, semente e polpa), e contando-se as sementes. As massas foram obtidas utilizando-se de balança analítica digital. Paralelamente, foram realizadas as análises químicas, determinando-se o teor de sólidos solúveis (grau brix) através de um refratômetro, e a acidez por titulação de $10 \mathrm{ml}$ de suco dos frutos com uma solução $0,1 \mathrm{~N}$ de hidróxido de sódio, utilizando-se de fenolftaleína como indicador, sendo o resultado expresso em percentagem de ácido cítrico.

Os resultados obtidos foram analisados estatisticamente, e as médias dos tratamentos foram confrontadas, utilizando-se do teste de Tukey, a 5\% de probabilidade.

\section{RESULTADOS E DISCUSSÃO}

De acordo com a Tabela 1, observou-se um intervalo de 44 dias da poda à antese (polinização) e 101 dias da polinização à maturação fisiológica dos frutos (caracterizada pelo início do afastamento dos carpelos), totalizando 145 dias da poda à colheita. Resultados semelhantes foram encontrados por Silva (2000) nas condições do município de Caraíbas-BA, para plantas podadas no mês de setembro. Já Kavati (1997) relatou o intervalo de 110 a 120 dias da antese ao amadurecimento dos frutos para as condições do Estado de São Paulo. Essas variações ocorrem devido a fatores ambientais. Silva (2000) observou que, com a elevação da temperatura e aumento do fotoperíodo, ocorre redução no número de dias, com relação ao desenvolvimento do fruto.

TABELA 1- Número de dias para cada intervalo de operações realizadas no experimento. Tanhaçu-BA, 2000.

\begin{tabular}{cc}
\hline Intervalos de operações & Número de dias \\
\hline Poda/ polinização & 44 \\
Polinização/ colheita & 101 \\
Poda/Colheita & 145 \\
\hline
\end{tabular}

Os dados relativos ao vigor das flores encontram-se na Tabela 2. Observa-se que houve diferença significativa para a massa das flores, sendo que médias superiores foram obtidas pelos tratamentos com ramos de maior diâmetro. Com estas observações, pode-se afirmar que os ramos com maior diâmetro produziram novos ramos vegetativos com botões florais de maior vigor. É provável que isso tenha ocorrido devido à maior disponibilidade de reservas nos ramos mais grossos.

TABELA 2- Médias da massa, do comprimento e do diâmetro das flores da pinheira obtidas para os diferentes diâmetros de ramos podados. Tanhaçu- BA, 2000.

\begin{tabular}{lccc}
\hline Tratamento & $\begin{array}{c}\text { Massa } \\
(\mathrm{g})\end{array}$ & $\begin{array}{c}\text { Comprimento } \\
(\mathrm{cm})\end{array}$ & $\begin{array}{c}\text { Diâmetro } \\
(\mathrm{cm})\end{array}$ \\
\hline T1- Ramos grossos & $0,93 \mathrm{a}$ & $2,84 \mathrm{a}$ & $0,86 \mathrm{a}$ \\
T2- Ramos medianos & $0,68 \mathrm{~b}$ & $2,83 \mathrm{a}$ & $0,82 \mathrm{~b}$ \\
T3- Ramos finos & $0,62 \mathrm{c}$ & $2,72 \mathrm{a}$ & $0,81 \mathrm{~b}$ \\
CV $(\%)$ & 4,62 & 6,42 & 2,41
\end{tabular}

Médias seguidas por letras iguais na mesma coluna não diferem significativamente entre si, pelo teste de Tukey, a 5\% de probabilidade.

Não foi constatada diferença estatística entre os tratamentos para o comprimento das flores; porém, em relação ao diâmetro das mesmas, observaram-se maiores médias para flores oriundas das podas de ramos grossos. Entre ramos finos e medianos, não se constataram diferenças significativas.

Em relação ao tamanho dos frutos por ocasião da colheita (Tabela 3),observou-se que os diferentes diâmetros dos ramos não influenciaram o peso, diâmetro e comprimento do fruto.

TABELA 3- Médias da massa, do comprimento e do diâmetro dos frutos obtidas para os diferentes diâmetros de ramos podados. Tanhaçu- BA, 2000.

\begin{tabular}{lccc}
\hline Tratamento & $\begin{array}{c}\text { Massa } \\
(\mathrm{g})\end{array}$ & $\begin{array}{c}\text { Comprimento } \\
(\mathrm{cm})\end{array}$ & $\begin{array}{c}\text { Diâmetro } \\
(\mathrm{cm})\end{array}$ \\
\hline T1-Ramos grossos & $230,55 \mathrm{a}$ & $7,70 \mathrm{a}$ & $7,88 \mathrm{a}$ \\
T2-Ramos medianos & $252,15 \mathrm{a}$ & $8,02 \mathrm{a}$ & $8,17 \mathrm{a}$ \\
T3-Ramos finos & $258,69 \mathrm{a}$ & $7,96 \mathrm{a}$ & $8,26 \mathrm{a}$ \\
CV $(\%)$ & 9,02 & 3,44 & 4,08
\end{tabular}

Médias seguidas por letras iguais na mesma coluna não diferem significativamente entre si, pelo teste de Tukey, a 5\% de probabilidade.

A constatação de que as podas nos ramos mais grossos produziram flores mais vigorosas, não acontecendo o mesmo com os frutos, nega a afirmação feita por Kavati (1997), de que existe uma correlação positiva entre o tamanho da flor e o fruto produzido. Provavelmente, a explicação para essa ocorrência deve-se ao fato de que as reservas acumuladas nos ramos não influenciam apenas no crescimento do fruto, pois estes também crescem em função do número de folhas em processo de fotossíntese.

O comprimento, diâmetro e peso obtidos para os frutos estão próximos aos encontrados por Popenoe (1920), Braga (1960), Beerh et al. (1983), Gardner \& Chaudhri (1985), Manica (1997), Donadio (1997), Araújo et al. (1999) e Carvalho et al.(2000).

O crescimento dos frutos, medido pelo comprimento e diâmetro, está representado nas Figuras 1 e 2, respectivamente. Observa-se que os ramos grossos, medianos e finos proporcionaram um crescimento uniforme aos frutos, não havendo variações na sua velocidade.

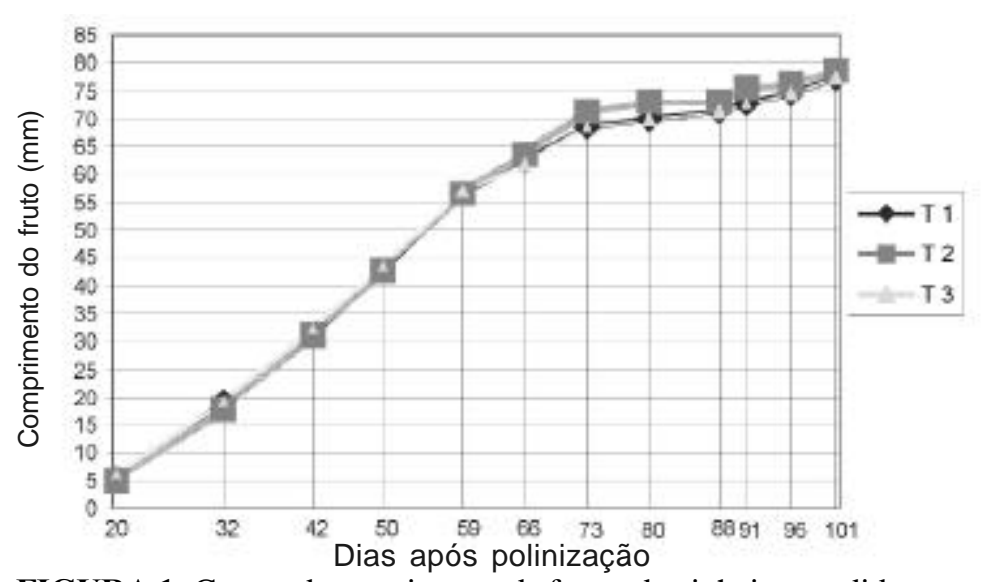

FIGURA 1- Curvas de crescimento de frutos de pinheira, medidas através do comprimento, para diferentes diâmetros de ramos podados. Tanhaçu-BA, 2000. 


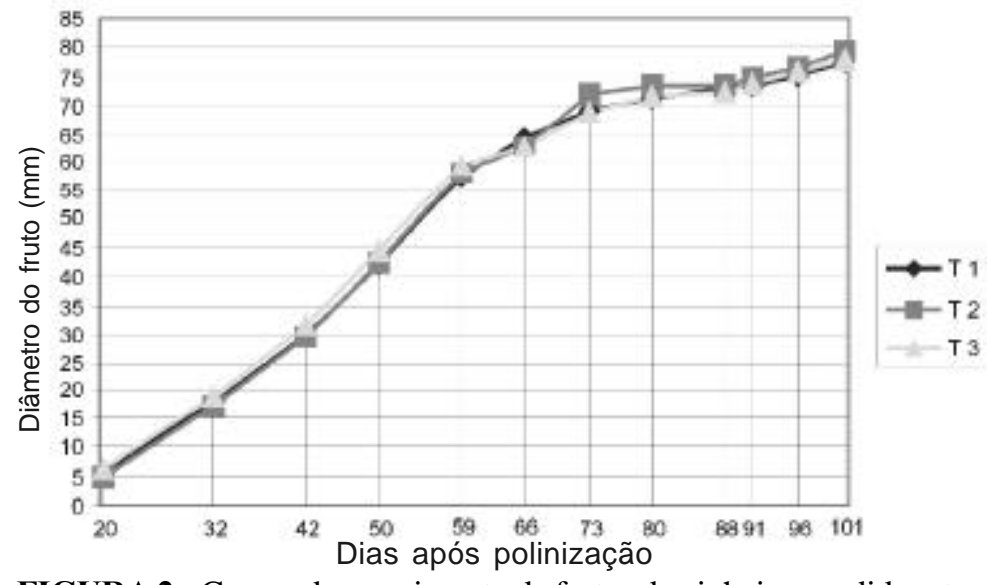

FIGURA 2 - Curvas de crescimento de frutos de pinheira, medidas através do diâmetro, para diferentes diâmetros de ramos podados. Tanhaçu-BA, 2000.

Após a polinização, constataram-se três períodos de crescimento do fruto definidos por: 1- rápido crescimento, do início até os 59 dias de desenvolvimento; 2 - velocidade de crescimento reduzida, dos 59 aos 88 dias; 3- nova aceleração do crescimento, dos 88 aos 101 dias, quando os frutos atingiram a maturação fisiológica. Estes três períodos que tiveram a duração de 59; 29 e 13 dias, respectivamente, também foram constatados por Silva (2000) no município de Caraíbas-BA, porém, com a duração de 48; 36 e 17 dias, respectivamente, para os três períodos. Esta variação, provavelmente, ocorreu em função de fatores como fotoperíodo, temperatura, tipo de solo e condições agroecológicas e de manejo em geral, em que as plantas se desenvolveram.

Quanto ao crescimento das brotações, avaliado pelo comprimento dos ramos novos surgidos após a poda, observou-se que as brotações provenientes dos ramos mais grossos apresentaram um crescimento superior, como demonstram as médias contidas na Tabela 4. Segundo Kavati (1997), os ramos crescem de 10 a 70 cm, em 6 meses, nas condições do Estado de São Paulo com temperatura e umidade elevadas. Nas condições estudadas, os ramos cresceram de 23,64 a 94,51 cm durante o período de 5 meses. Tais variações se devem a fatores ambientais e manejo das plantas. Quanto ao crescimento do diâmetro dos ramos efetivamente podados, a velocidade de crescimento foi semelhante para os diferentes diâmetros que cresceram em torno de $3 \mathrm{~mm}$ a partir da poda até a colheita dos frutos.

TABELA 4- Médias do comprimento de brotações de pinheira obtidas para diferentes diâmetros de ramos podados após cinco meses. Tanhaçu-BA, 2000.

\begin{tabular}{lc}
\hline Tratamentos & Comprimento $(\mathrm{cm})$ \\
\hline T1- Ramos grossos $(11-14 \mathrm{~mm})$ & $94,51 \mathrm{a}$ \\
T2- Ramos medianos $(7-10 \mathrm{~mm})$ & $61,96 \mathrm{~b}$ \\
T3- Ramos finos $(3-6 \mathrm{~mm})$ & $23,64 \mathrm{c}$ \\
CV $(\%)$ & 11,81 \\
\hline
\end{tabular}

Médias seguidas por letras iguais na mesma coluna não diferem significativamente entre si, pelo teste de Tukey, a 5\% de probabilidade.

Com relação às partes componentes dos frutos (Tabela 5), verificou-se maior percentual de casca + engaço, seguidos pela polpa e pelas sementes para todos os tratamentos, confirmando as características citadas por Holschut et al. (1987) e Kavati (1997) e discordando dos resultados obtidos por Maia et al. (1986) e Dantas et al. (1991), que encontraram a polpa como principal constituinte.

Para as características químicas dos frutos, as análises realizadas não demonstraram diferenças significativas entre os tratamentos (Tabela 6), que apresentaram teores médios de sólidos solúveis totais entre 19,73 e 20,53 graus brix. Já os dados obtidos por Silva (2000) ficaram entre 21,54 a $24,50^{\circ}$ brix .

No que se refere à acidez total titulável, expressa em porcentagem de ácido cítrico, os resultados ficaram próximos aos índices encon- trados por Dantas et al. (1991), que foi abaixo de 0,24\% para as seleções oriundas de Pernambuco e Alagoas, e por Maia et al. (1986), que foi de 0,21\% para pinhas do Estado do Ceará. As variações observadas entre os resultados obtidos por diversos autores podem ser explicadas pelo fato da grande variabilidade genética apresentada pela cultura da pinheira, além da influência do grau de maturação antes da colheita e condições de armazenamento utilizadas.

TABELA 5- Resultados das análises físicas do fruto da pinheira em completo estádio de maturação. Tanhaçu-BA, 2000.

\begin{tabular}{lcccc}
\hline Tratamento & $\begin{array}{c}\text { Casca }+ \\
\text { engaço }(\%)\end{array}$ & $\begin{array}{c}\text { Polpa } \\
(\%)\end{array}$ & $\begin{array}{c}\text { Sementes } \\
(\%)\end{array}$ & $\begin{array}{c}\mathrm{N}^{\mathbf{o}} \text { de } \\
\text { sementes }\end{array}$ \\
\hline T1- Ramos grossos & 51,60 & 38,36 & 10,0 & 66 \\
T2- Ramos medianos & 53,85 & 37,01 & 9,1 & 61 \\
T3- Ramos finos & 50,32 & 40,36 & 9,4 & 53 \\
\hline
\end{tabular}

TABELA 6- Resultados das análises químicas da pinheira em completo estádio de maturação. Tanhaçu-BA, 2000.

\begin{tabular}{lcc}
\hline Tratamento & brix & Acidez total titulável (\%) \\
\hline T1- Ramos grossos & $19,73 \mathrm{a}$ & $0,2217 \mathrm{a}$ \\
T2- Ramos medianos & $21,19 \mathrm{a}$ & $0,2510 \mathrm{a}$ \\
T3- Ramos finos & $20,53 \mathrm{a}$ & $0,2286 \mathrm{a}$ \\
CV $(\%)$ & 7,58 & 10,31
\end{tabular}

Médias seguidas por letras iguais na mesma coluna não diferem significativamente entre si, pelo teste de Tukey, a 5\% de probabilidade.

\section{CONCLUSÕES}

Nas condições em que este trabalho foi desenvolvido, concluise que os ramos de pinheira com maior diâmetro imprimem maior vigor às brotações e flores, mas não afetam a velocidade de crescimento e características fisico-químicas dos frutos.

\section{REFERÊNCIAS BIBLIOGRÁFICAS}

ARAÚJO, J. F.; ARAÚJO J. F.; ALVES, A. A. C. Instruções técnicas para o cultivo da pinha (Annona squamosa L.). Salvador, BA: EBDA, 1999. 44p. (Circular Técnica, n. 7).

BEERH, O. P.; GIRIDHAR. N.; RAGHURAMAIAH, B. Custard apple (Annona squamosa L.) Part I - Physico-morphological characters and chemical composition. Indian Food Packer, Calcutá, v.3, p.37, 1983.

BRAGA, R. Plantas do Nordeste, especialmente do Ceará. 2. ed. Fortaleza: Imprensa Oficial, 1960. p.53-54.

CARVALHO, P. S. de; BEZERRA, J. E. F.; LEDERMAN, I. E. Avaliação de genótipos de pinheira (Annona squamosa L.) no Vale do Rio Moxotó III- características de crescimento e produção- 1992 a 1997. Revista Brasileira de Fruticultura., Jaboticabal, v. 22, n. 1, p. 27-30, abr. 2000.

CAVALCANTI, R. L. R. R. A cultura da pinha (Annona squamosa L.). In: ENCONTRO ESTADUAL DE FRUTICULTURA, 1., 1993, Cruz das Almas. EMBRAPA/CNPMF, 1993. 159p. (Documento, 39).

DANTAS, N. P.; BEZERRA, J. E. F.; PEDROSA, A. C.; LEDERMAN, I. E. Características físico-químicas de frutos de pinheira (Annona squamosa L.) oriundos de Pernambuco e Alagoas. Revista Brasileira de Fruticultura, Cruz das Almas, v. 13, n. 1, p. 11-116, out. 1991.

DONADIO, L.C. Melhoramento de atemoya e cherimólia. In: SÃO JOSÉ, A. R.; SOUZA, I. V. B.; MORAIS, O. M.; REBOUÇAS, T. N. H. Anonáceas, produção e mercado (Pinha, Graviola, Atemóia e Cherimólia). Vitória da Conquista-BA: DFZ/UESB, 1997. p. 43-34.

GARDNER, R.J.; CHAUDHRI, S. A. The propagation of tropical fruit trees. 4.ed. England: FAO/CAB, 1985. 566p.

HOLSCHUH, H. S.; NARAIN, N.; BORA, P. S.; VASCONSELOS, M. A. da S.; SANTOS, C. M. G. dos. Caracterização física de frutos de pinha 
oriundos do trópico, semi-árido da Paraíba. In: CONGRESSO BRASILEIRODEFRUTICULTURA, 9., 1987, Campinas. Anais...Campinas: Sociedade Brasileira de Fruticultura, 1988. p.669-673.

KAVATI, R. Melhoramento em fruta-do-conde. In: SÃO JOSÉ, A. R.; SOUZA, I. V. B.; MORAIS, O. M.; REBOUÇAS, T. N. H. Anonáceas, produção e mercado (Pinha, Graviola, Atemóia e Cherimólia). Vitória da Conquista, BA: DFZ/UESB, 1997. p. 47-54.

KSHIRSAGAR, S.V.; SHINDE, N.N.; RANE, D.A. Studies on the floral biology in atemoya (Annona atemoya), South Indian Horticulture, Indian, v.23, p.6-10, 1975.

KAVATI, R.; PIZA JUNIOR, C. de T. Formação e manejo do pomar de fruta-do-conde, atemóia e cherimólia. In: SÃO JOSÉ, A. R.; SOUZA, I. V. B.; MORAIS, O. M.; REBOUÇAS, T. N. H. Anonáceas, produção e mercado (Pinha, Graviola, Atemóia e Cherimólia). Vitória da Conquista-BA: DFZ/UESB, 1997. p. 75-83.

LEON, A.J. Botánica de los cultivos tropicales. San José : Serviço editorial IlCA, 1987.445p.

MAIA, G. A.; MESQUITA FILHO, J. A. de; BARROSO, M. A. T.;
FIGUEIREDO, R. W. de. Características físicas e químicas da ata. Pesquisa Agropecuária Brasileira, Brasília, v. 21, n.10, p.1073-1076, 1986.

MANICA, I. Taxonomia, morfologia e anatomia. In: SÃO JOSÉ, A. R.; SOUZA, I. V. B.; MORAIS, O. M.; REBOUÇAS, T. N. H. Anonáceas, produção e mercado (Pinha, Graviola, Atemóia e Cherimólia). Vitória da Conquista-BA: DFZ/UESB, 1997. p. 20-35.

MARTELETO, L.A.P. Situação atual e perspectivas de anonáceas no Estado do Rio de Janeiro. In: SÃO JOSÉ, A. R.; SOUZA, I. V. B.; MORAIS, O. M.; REBOUÇAS, T. N. H. Anonáceas, produção e mercado (Pinha, Graviola, Atemóia e Cherimólia). Vitória da ConquistaBA: DFZ/UESB, 1997. p.178-179.

POPENOE, N. Manual of tropical and subtropical fruits. New York: The Macmillan Company, 1920.474p.

SILVA, A. C. da.Épocas de poda e métodos de polinização na produção da pinheira (Annona squamosa L.). 2000. 101f. Dissertação (Mestrado em Fruticultura) - Escola de Agronomia, Universidade Federal da Bahia, Cruz das Almas, 2000. 